\title{
Survival rates and causes of mortality of roe deer Capreolus capreolus in a rural landscape, eastern Poland
}

\author{
Leif Sönnichsen $^{1}$ (D) Tomasz Borowik ${ }^{1}$ - Tomasz Podgórski ${ }^{1} \cdot$ Kamila Plis $^{1}$ • \\ Anne Berger $^{2} \cdot$ Bogumila Jędrzejewska $^{1}$
}

Received: 27 October 2016 / Accepted: 21 February 2017 / Published online: 10 March 2017

(C) The Author(s) 2017. This article is published with open access at Springerlink.com

\begin{abstract}
Game species in the cultural landscapes of Europe are exposed to several sources of anthropogenic pressure. Whilst hunting is part of coordinated wildlife management, poaching is difficult to quantify, and hence, relatively little is known about its impact on survival patterns of game species. We estimated survival and cause-specific mortality rates of 31 roe deer Capreolus capreolus in the surroundings of the Białowieża Primeval Forest, eastern Poland, from 2010 to 2013. The study area consisted of large, extensively used agricultural fields and a mosaic of pine plantations, which were interspersed with natural forest stands and small agricultural fields and meadows. Roe deer were regularly hunted and the forested part of the study area was traversed by large carnivores. Annual survival rate of all deer was 0.69 and did not differ between seasons. Annual survival rates of females and males in each age class (young and adult) were similar. Poaching was a major source of mortality ( 6 out of 13 roe deer deaths), and poachers did not prefer any sex or age. Adult survival (0.77) was higher than survival of young individuals (0.53); this trend was stronger when poaching was excluded from the analysis. All cases of poaching were recorded between mid-September and February. Although the two parts
\end{abstract}

Communicated by: Dries Kuijper

Electronic supplementary material The online version of this article (doi:10.1007/s13364-017-0308-2) contains supplementary material, which is available to authorized users.

Leif Sönnichsen

leif.soennichsen@gmx.de

1 Mammal Research Institute, Polish Academy of Sciences, ul. Waszkiewicza 1, 17-230 Białowieża, Poland

2 Leibniz Institute for Zoo and Wildlife Research, Alfred-Kowalke-Straße 17, 10315 Berlin, Germany of the study area were exposed to a similar degree of anthropogenic pressure, all poached individuals occupied home ranges in the mosaic, where the forest cover in home ranges of roe deer was significantly higher than in the field.

Keywords Capreolus capreolus · Game management . Poaching $\cdot$ Forest-field mosaic $\cdot$ Open fields $\cdot$ Autumn-winter season

\section{Introduction}

Roe deer Capreolus capreolus is a widespread and popular game animal species (Cederlund et al. 1998; Mysterud et al. 2006), intensively hunted in Europe (Apollonio et al. 2010). Therefore, human harvest is an important mortality factor in managed deer populations (Langvatn and Loison 1999). In addition to hunting, natural causes of mortality such as predation (Okarma et al. 1995; Aanes and Andersen 1996; Melis et al. 2009), climatic factors (Gaillard et al. 1993; Gaillard et al. 1998), male-male interaction and diseases (Aguirre et al. 1999) occur and vary between age classes and sexes (Loison et al. 1999). These factors may act differently at various levels of deer population densities and resource availability (Pettorelli et al. 2003). Earlier studies on roe deer survival were conducted in areas where large predators were not present (e.g., Gaillard et al. 1993; Loison et al. 1999) but investigated the influences of red foxes Vulpes vulpes (Aanes and Andersen 1996) and wild boar Sus scrofa (Van Moorter et al. 2009) on juvenile survival.

Beside natural mortality factors and legal human hunting, poaching is a genuine threat not only to endangered but also to common wildlife species (Muth and Bowe 1998). Evidence from the turbulent twentieth century shows that wars and socioeconomic shocks strongly affect game populations through 
massive poaching. The erosion of wildlife protection system in Białowieża Primeval Forest (E Poland) in 1915-1920 (World War I, Polish-Soviet War) caused extermination of the local populations of European bison Bison bonasus and moose Alces alces and decimation of red deer Cervus elaphus, roe deer and wild boar (Jędrzejewska et al. 1997). The collapse of communism in the former Soviet Union in 1991 caused a sharp increase in poverty and led to declines of ungulate populations due to overexploitation - a phenomenon well documented in Belarus (Sidorovich et al. 2003) and throughout Russia (Bragina et al. 2015). In socioeconomically stable periods, the impact of poaching is likely released and its role in ungulate mortality would rather depend on the local rules and enforcements of wildlife protection (Okarma et al. 1995; Kamler et al. 2007).

We studied survival and cause-specific mortality rates of radio-collared roe deer in the surroundings of the Białowieża Primeval Forest (BPF), eastern Poland, in 2010-2013. In our study area, roe deer were exposed to hunting and other forms of human disturbances such as farming and wood cutting. Free-roaming dogs Canis lupus familiaris occurred in high densities (K. Plis and co-workers, unpublished data), and one part of the study area was traversed by wolves $C$. lupus and lynx Lynx lynx.

\section{Study area}

Roe deer were captured and radio-tracked in the south-western outskirts of the BPF $\left(52^{\circ} 47^{\prime} \mathrm{N}-52^{\circ} 38^{\prime} \mathrm{N}, 23^{\circ} 19^{\prime} \mathrm{E}-23^{\circ} 34^{\prime}\right.$ E). The study area $\left(148 \mathrm{~km}^{2}\right)$ was divided in a forest-field mosaic $\left(39 \mathrm{~km}^{2}\right)$ and an open field part $\left(109 \mathrm{~km}^{2}\right)$ (Fig. 1). The forest-field mosaic part was characterised by coniferous and deciduous tree plantations, interspersed by meadows and relatively small agricultural fields. This part was connected with the large forest complex of the BPF and was traversed by wolves and lynx, which preyed on roe deer (Jędrzejewski et al. 2002; Okarma et al. 1995, 1997). The presence of large carnivores was recorded during fieldwork, and their densities were estimated in the woodlands of BPF by the annual census of large carnivores. The censuses estimated an average wolf and lynx density of 3.5 and 2.5 individuals $/ 100 \mathrm{~km}^{2}$, respectively (data of Mammal Research Institute PAS, Białowieża). The field part consisted of large, extensively used agricultural areas, on which large carnivores were rarely found.

Traditional rural settlements were distributed over the entire study area. Villages consisted mainly of wooden houses and farm buildings. Farms were small with an average size of 11 ha (K. Plis and co-workers, unpublished). On average, 28 people lived per $\mathrm{km}^{2}$ (Central Statistical Office 2011), and human population showed a tendency to decline. Over $45 \%$ of the inhabitants were older than 50 years. Density of stray dogs was assessed at 32 inds $/ 100 \mathrm{~km}^{2}$ (K. Plis and coworkers, unpublished).
Roe deer population density was estimated at a minimum density of $4.2 \mathrm{inds} / \mathrm{km}^{2}$ in the mosaic part of the study area and 2 inds $/ \mathrm{km}^{2}$ in the open part (Reil 2010). Density of roe deer was relatively low but comparable to roe deer densities in the Białowieża Primeval Forest, which were annually surveyed (1.2 inds $/ \mathrm{km}^{2}$; Wawrzyniak et al. 2010). Roe deer were legally hunted in both parts of the study area. During the period of this study (2010-2013), the hunting bag ranged from 36 to 46 deer per year (equivalent to $0.24-0.31 \mathrm{deer} / \mathrm{km}^{2}$ ).

In 2010-2013, the mean temperature of January varied from -5.3 to $-1.0{ }^{\circ} \mathrm{C}$ and that of July from 20.9 to $21.9{ }^{\circ} \mathrm{C}$. Mean annual precipitation was $683 \mathrm{~mm}$ and ranged from 585 to $866 \mathrm{~mm}$. Average number of days with snow cover during winter was 94 (range 51-123 days; www.weatheronline.pl).

\section{Methods}

Roe deer were trapped with drop-down nets and box traps baited with maize. Trapping of individuals included in this study occurred in January-March and December 2010 and in January-March 2011. After capture, roe deer were immobilised with a mixture of ketamine and xylazine and were equipped with either a very high frequency (VHF) collar (Televilt) (14 individuals) or a Global Positioning System (GPS) collar (Vectronic Aerospace, GPS-Plus 1 and GPS PROLIGHT) (17 individuals). After collaring, roe deer received an antidote (Antisedan) and were released. For the analyses, individuals were clustered into two age classes, which are young $(<24$ months) and adults ( $>24$ months) based on teeth abrasion and in the case of juveniles based on the presence of a tri-cuspid third pre-molared milk tooth (Ratcliffe and Mayle 1992; Stubbe 1997). The handling protocol of roe deer has been approved by the Local Ethical Commission, Białystok, Poland.

VHF-collared roe deer were radio-tracked on average ten times per month, and at least once per season, each animal was continuously followed for $24 \mathrm{~h}$. GPS collars were programmed to take one location every seventh hour and one continuous 24-h tracking session per month. During the 24-h tracking, locations were taken every $15 \mathrm{~min}$. All collars were equipped with a mortality signal, which helped us to determine the fate of the collared roe deer. The signal of the VHF collars has changed after $24 \mathrm{~h}$ of inactivity to a higher occurrence indicating a mortality event. The GPS collars were equipped with a mortality sensor, which is basically a simplified activity sensor in order to create a mortality event if the collar has not been moved for $12 \mathrm{~h}$. However, in the case of poached individuals, the mortality signal was not reliable, as the collar was moved by the poacher after the individual died. Hence, the exact date of death was estimated by assessing differences of locations, movements and activity patterns based on previously recorded data. 
Fig. 1 Map of the study area and centroids of $90 \% \mathrm{MCP}$ home ranges of collared roe deer during the study period (2010-2013).

Different symbols for the centroids represent the fate (survived, natural death, poached) of the individual. Young individuals (black colour); adult (white colour with solid outline); and individuals, which aged from young to adult during the study (grey circles with a black solid outline)

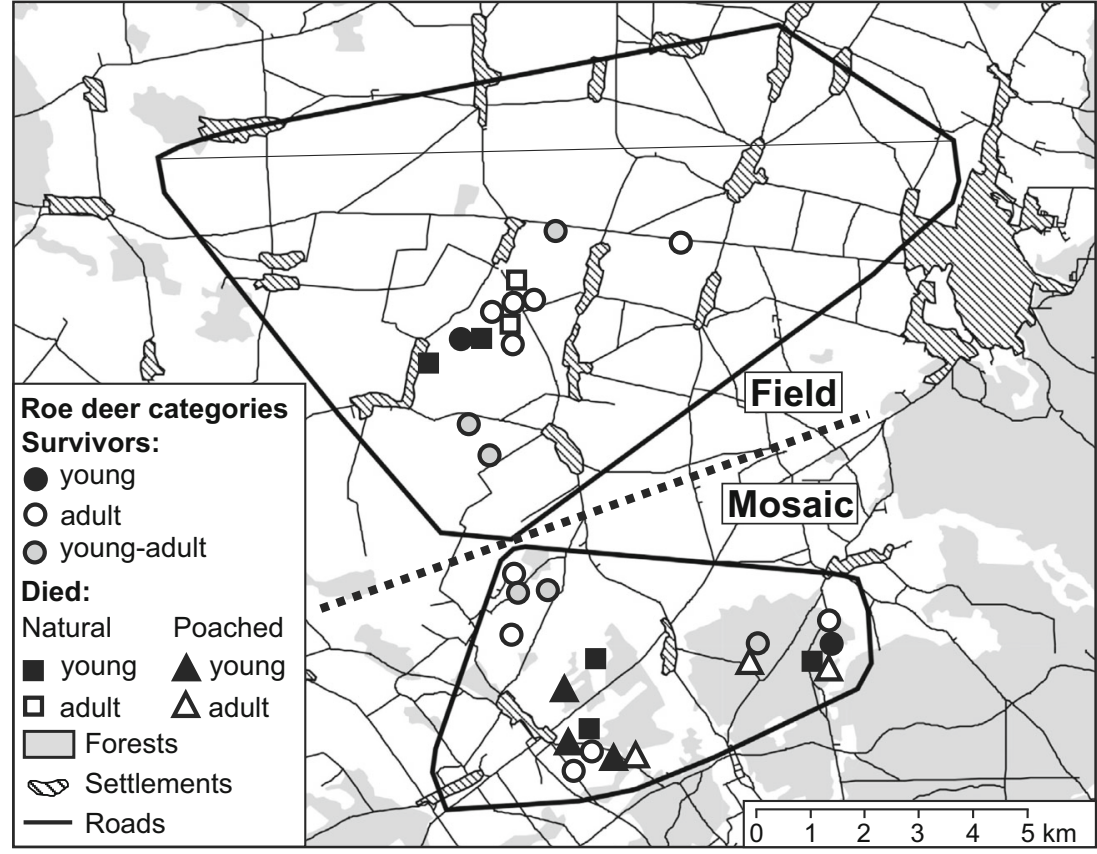

Causes of death were classified into two groups, which are poaching and natural. Because of the low sample size of natural causes of death, all deaths without a sign of anthropogenic origin were considered natural, and they included starvation/ disease, violent interaction between two males, predation and unknown. We presumed natural cause of death when we found collared animal carcass in either poor body condition (pointing at starvation/disease), showing clear signs of predation, such as bite marks on the body and the collar, or as a result of observed intra-specific aggression. We considered the cause of death as unknown, when we found the remains of the dead individual, but could not explicitly identify the cause of death (usually scavengers or dogs fed on the carcasses before) and did not find any sign of a human cause of death. Amongst the unknown causes of deaths were two individuals of which we retrieved only the collars but could not confirm poaching. In one case, the area where the collar was found was not accessible for a long period during winter, and in another case, we retrieved the collar from a farmer, who had found it.

We considered an individual as animal poached when (1) we found the intact collar and no remains but hair of the individual in the vicinity of the collar and (2) this happened outside the hunting season or we found the collar in an area, where no hunting quotas for roe deer were given to hunters (Puszcza Hunting Club). We presumed that poachers would be interested in collecting the entire carcass to make the most of their harvest and to conceal their activity. Additionally, in one case, we were able to analyse collar locations prior to its retrieval and have detected unnatural collar dislocations, such as rapid movements into a settlement and outside of the animal's core range, which indicated poaching event. Afterwards, the intact collar was placed close to a road. We assume that it was easier for poachers to leave the collar unharmed or deposit it close to a road than to destroy it. It was very unlikely that roe deer lost their collars, because collars were fixed tightly on the animals' neck, and we never observed such event during the study. During fieldwork, no snares were found in the study area.

Transmitter-days were calculated between the date of the first collar employment and the date of the last regular radiotracking location before the collar stopped working or the animal died. Annual survival and cause-specific mortality were calculated for young females and males and adult females and males using the program MicroMort (Heisey and Fuller 1985). We tested for differences between season, sexes and age classes using $Z$ tests for two-way comparisons (Pollock et al. 1989). We distinguished between autumn/ winter (September-February) and spring/summer (MarchAugust) to account for changes in climate and vegetation.

Additionally, we calculated $90 \%$ minimum convex polygon home range and the corresponding home range centroid for each individual during the monitored period, and in each home range, we estimated habitat features such as road density (forest and paved roads) and percentage of forest cover and assigned each individual to one of the two different habitat types "mosaic" or "field". Additionally, we calculated the distance of the home range centroid to the next settlement. Annual survival and cause-specific mortality were estimated for individuals in the mosaic and field. We tested for differences between the two habitats in road density and forest cover per home range as well as for differences in the distance of the home range centroid to the nearest settlement using a Mann-Whitney test. Analyses were done using R 2.15.1 and ArcMap 9.3.1. 


\section{Results}

In total, we captured 33 roe deer that were monitored from 2010 to 2013. Two radio collars failed to work directly after employment and were not included into the analyses. Six individuals were tracked as they aged from young to adult (Table S1, Online Resource 1) (Fig. 1). Considering those cases, the final sample size for estimating survival and cause-specific mortality rates included 37 individuals and 13,487deer-days (Table 1). Average tracking time per individual was $435 \pm 40$ (mean \pm SE) days. We recorded 13 deaths, 6 (46\%) by poachers and 7 (54\%) from natural reasons. The latter included starvation/disease (one individual), violent interaction between two males (one), predation by lynx (one) and unknown (four). On average, $417 \pm 101$ (mean \pm SE) days passed between collaring and the time we retrieved the collar from presumably poached individuals. Tracking time for naturally died individuals was lower ( $231 \pm 67$ days, mean \pm SE), but differences were not significant (Mann-Whitney $U$ test, $n=13, p=0.20$ ).

Annual survival rate of all deer was 0.69 . Although causespecific mortality varied between seasons (see below and Table 1), survival did not differ significantly $(Z=0.95$, $p=0.34$ ) between winter (0.77) and summer (0.89). Hence, seasons were pooled for further survival analyses. Annual survival of young males $(0.46)$ and young females $(0.57)$ did not differ $(Z=0.42, p=0.68)$. Annual survival did not differ $(Z=0.79, p=0.43)$ between adult males $(0.70)$ and adult females (0.83), either. Hence, we also pooled sexes in each age class for further analyses. Although annual survival in adults $(0.77)$ was higher than in young $(0.53)$, the differences were not significant $(Z=-1.56, p=0.12)$. When excluding poaching and considering only natural sources of death, differences in survival were significantly $(Z=-1.99, p=0.05)$ higher in adults $(0.92)$ than in young $(0.65)$.

Recorded poaching happened exclusively during autumn and winter (between mid-September and February; Table S1, Online Resource 1). Hence, the mortality rate due to poaching during autumn and winter (0.17) was significantly higher than during spring and summer $(0)$, when young and adult individuals were pooled $(Z=2.68, p=0.01)$. No significant seasonal differences $(Z=-1.31, p=0.19)$ were detected in mortality from natural factors $(0.06$ in autumn-winter, 0.11 in springsummer; Table 1).

Average road density in home ranges of collared roe deer was $32.6 \pm 1.1$ (mean $\pm \mathrm{SE}) \mathrm{m} / \mathrm{h}$, and forest cover ranged from 0 to $100 \%$ (Table S1, Online Resource 1). Road density in home ranges was similar (Mann-Whitney $U$ test, $n=31$, $p=0.77$ ) in the mosaic (mean $\pm \mathrm{SE}=31.9 \pm 1.8 \mathrm{~m} / \mathrm{ha}$ ) and the field $(33.6 \pm 0.8 \mathrm{~m} / \mathrm{ha})$, but percentage of forest cover per home range was significantly (Mann-Whitney $U$ test, $n=31$, $p<0.01$ ) higher in the mosaic (mean $\pm \mathrm{SE}=45.9 \pm 6.3$ ) than in the field $(0.7 \pm 0.6)$ (see also Fig. 1). No differences (Mann-
Whitney $U$ test, $n=31, p=0.59$ ) were detected between the distances of home range centroids to the nearest settlement in the field $(940.7 \pm 89.6 \mathrm{~m})$ and in the mosaic $(1133.6 \pm 138.9 \mathrm{~m})$.

Survival of roe deer was higher in the field (0.79) than in the mosaic $(0.60)$, although this difference was not significant $(Z=1.36, p=0.17)$. Collared individuals were exclusively poached in the mosaic part (Fig. 1). Hence, mortality rates due to poaching were significantly higher $(Z=-2.94, p<0.01)$ in the mosaic $(0.31)$ than in the field $(0)$. Natural mortality was higher in the field $(0.21)$ than in the mosaic $(0.08)$, but differences were not significant $(Z=1.81, p=0.07)$.

\section{Discussion}

Poaching was the most important cause of death of collared roe deer in the surroundings of the BPF. Former studies showed that in the contiguous woodlands of BPF (state forests and a national park), all five species of ungulates suffered from poaching, yet the percentage of recorded deaths (excluding hunting exploitation) that was prescribed to poaching (from 7\% in roe deer to $32 \%$ in moose; Okarma et al. 1995; Kamler et al. 2007) was much lower than in our study area (largely private land with smaller proportion of state forests). Therefore, the local rules and enforcements of wildlife protection seem decisive for the level of poaching in the relatively stable period of last decades.

Roe deer from both age classes and sexes were poached, and no significant differences in survival rates between adults and young were detected when poaching was included in the analyses. This indicates that poachers were unselective and not interested in trophies. Furthermore, as no carcasses of poached animals remained in the study area, we assume that roe deer was the target species, killed for meat. Poaching of collared individuals took place exclusively during autumn and winter. We believe that a popular poaching technique was to shoot roe deer either from a car or whilst stalking during periods with less dense vegetation when individuals could be easier spotted. During fieldwork, we found no evidence of the use of snares. Furthermore, all poached individuals occupied home ranges within the mosaic part of the study area, which had a significantly higher forest cover than the field part. In forested areas, poachers would be less likely observed by other people than in open fields. Also, if poachers used cars in forested areas, it was possibly difficult for the deer to detect the approaching vehicle early enough.

Several causes of death of collared roe deer were summarised as of natural origin as each of them occurred rarely. Low predation of collared deer by lynx and no recorded cases of predation by wolves were not surprising as open fields and field-forest mosaic are marginal or even unsuitable habitat for both large carnivores (Niedziałkowska et al. 2006; 
Table 1 Annual survival and cause-specific mortality rates of radio-collared roe deer Capreolus capreolus in the surroundings of the Białowieża Primaeval Forest, eastern Poland, in 2010-2013

\begin{tabular}{|c|c|c|c|c|c|c|}
\hline \multirow[t]{2}{*}{ Period (days) } & \multirow[t]{2}{*}{ Parameter } & \multicolumn{2}{|l|}{ Young } & \multicolumn{2}{|l|}{ Adults } & \multirow[t]{2}{*}{ Total } \\
\hline & & Females & Males & Females & Males & \\
\hline \multirow[t]{10}{*}{ Winter (181) } & $N$ deer & 9 & 3 & 10 & 9 & 31 \\
\hline & Radio-days & 1121 & 593 & 2000 & 1882 & 5596 \\
\hline & $N$ deaths (total) & 2 & 1 & 2 & 3 & 8 \\
\hline & Poaching & 1 & 1 & 2 & 2 & 6 \\
\hline & Natural & 1 & 0 & 0 & 1 & 2 \\
\hline & Survival & 0.72 & 0.74 & 0.83 & 0.75 & 0.77 \\
\hline & $(95 \% \mathrm{CI})$ & $(0.46-1)$ & $(0.40-1)$ & $(0.65-1)$ & $(0.54-1.00)$ & $(0.64-0.92)$ \\
\hline & \multicolumn{6}{|c|}{ Mortality rates $(95 \% \mathrm{CI})$} \\
\hline & Poaching & $0.14(0-0.39)$ & $0.26(0-0.70)$ & $0.17(0-0.38)$ & $0.17(0-0.38)$ & $0.17(0.05-0.30)$ \\
\hline & Natural & $0.14(0-0.39)$ & 0 & 0 & $0.08(0-0.24)$ & $0.06(0-0.13)$ \\
\hline \multirow[t]{10}{*}{ Summer (184) } & $N$ deer & 10 & 5 & 12 & 9 & 36 \\
\hline & Radio-days & 1520 & 793 & 2849 & 2729 & 7891 \\
\hline & $N$ deaths (total) & 2 & 2 & 0 & 1 & 5 \\
\hline & Poaching & 0 & 0 & 0 & 0 & 0 \\
\hline & Natural & 2 & 2 & 0 & 1 & 5 \\
\hline & Survival & 0.78 & 0.63 & 1 & 0.93 & 0.89 \\
\hline & $(95 \% \mathrm{CI})$ & $(0.56-1)$ & $(0.33-1)$ & 1 & $(0.82-1)$ & $(0.80-0.99)$ \\
\hline & \multicolumn{6}{|c|}{ Mortality rates $(M ; 95 \% \mathrm{CI})$} \\
\hline & Poaching & 0 & 0 & 0 & 0 & 0 \\
\hline & Natural & $0.22(0-0.48)$ & $0.37(0-0.78)$ & 0 & $0.07(0-0.19)$ & $0.11(0.02-0.20)$ \\
\hline \multirow[t]{10}{*}{ Annual (365) } & $N$ deer & 10 & 5 & 13 & 9 & 37 \\
\hline & Radio-days & 2641 & 1386 & 4849 & 4611 & 13,487 \\
\hline & $N$ deaths (total) & 4 & 3 & 2 & 4 & 13 \\
\hline & Poaching & 1 & 1 & 2 & 2 & 6 \\
\hline & Natural & 3 & 2 & 0 & 2 & 7 \\
\hline & Annual survival & 0.57 & 0.46 & 0.83 & 0.70 & 0.69 \\
\hline & $(95 \% \mathrm{CI})$ & $(0.32-1)$ & $(0.19-1)$ & $(0.65-1)$ & $(0.49-1)$ & $(0.56-0.84)$ \\
\hline & \multicolumn{6}{|c|}{ Mortality rates $(95 \% \mathrm{CI})$} \\
\hline & Poaching & $0.14(0-0.39)$ & $0.26(0-0.70)$ & $0.17(0-0.38)$ & $0.17(0-0.38)$ & $0.17(0.05-0.30)$ \\
\hline & Natural & $0.29(0.01-0.58)$ & $0.27(0-0.61)$ & 0 & $0.13(0-0.31)$ & $0.14(0.04-0.24)$ \\
\hline
\end{tabular}

CI confidence intervals

Jędrzejewski et al. 2008). Interestingly, none of the collared roe deer was killed by stray dogs, which were common in the area and local people reported seeing them hunting wildlife (K. Plis et al. unpublished). In the woodlands of BPF, lynx were recognised as the cause of death in $28 \%$ of roe deer carcasses, wolves in $23 \%$ and stray dogs in $4 \%$ (Okarma et al. 1995). Other studies reported roe deer killed by red foxes (Aanes and Andersen 1996) and wild boar (Van Moorter et al. 2009); however, these two factors were mainly important during the first 8 months of life, and all roe deer monitored in this study were older.

Mortality due to starvation/disease and/or severe winter conditions was surprisingly low even during winters with long periods of snow cover, which has been reported as important mortality factor in roe deer populations (Gaillard et al. 1993; Okarma et al. 1995). Although this study was based on radiocollared individuals, which were habituated to traps, we do not believe that the provided bait at the traps increased survival as we used it in moderate quantities.

Roe deer is one of the most important game species in Poland (Wawrzyniak et al. 2010) and in whole Europe (Cederlund et al. 1998). That no animals in our sample were harvested by hunters can be due to two reasons. First, hunters avoided to shoot collared individuals, and second, roe deer density was relatively low and hunters decreased their hunting bag voluntarily. On the other hand, collared individuals could have been easier to spot for poachers. But this would only be true for VHF-collared roe deer as those collars had 
conspicuous colours, whereas the belts of GPS collars were coloured inconspicuously. Three VHF-collared and three GPS-collared individuals were poached, which accounted for 21 and $18 \%$ of the collared individuals, respectively.

No significant differences in collared female and male survival were observed in our study. Similar adult survival rates of both sexes were reported before (Gaillard et al. 1993), although female survival was higher than male survival. Additionally, female-biased survival increased amongst old individuals (Loison et al. 1999).

In general, in our study, the survival of collared adults was higher than that of young, although the differences were not significant. However, when we excluded poaching as a mortality factor, survival of adult roe deer showed a strong trend to be higher than survival of young. Gaillard et al. (1993) found that the difference between survival of juvenile and adult roe deer varied between populations in France but stated that juveniles appear to be more sensitive to external influences than adults.

The population density of roe deer in our study area was low, and although the hunting bag corresponded to low numbers, poaching can undo the effects of this management approach, especially so because the roe deer density in the nearby woodlands of BPF has also been low $\left(1.2 \mathrm{inds} / \mathrm{km}^{2}\right)$. Metaanalysis of roe deer populations in Europe evidenced that topdown effects such as predation pressure by lynx and wolves have stronger effects on the species dynamics at low densities (Melis et al. 2009). Similar to the influence of predation pressure, high poaching rates in human-modified environments can keep ungulate numbers on a low level, below the habitat carrying capacity. Such a strong limiting role of poaching has been documented in ungulate populations in BPF during times of wars and unstable political and economic situation in the recent century (Jędrzejewska et al. 1997). Thus, our study showed that in human-altered environments, poaching can be a genuine threat to game species, and its effect should not be underestimated.

Acknowledgements L. Sönnichsen was funded by the Institute for Zoo and Wildlife Research (IZW), the Mammal Research Institute PAS, the Polish Ministry of Science and Higher Education (grants nos. KBN 2 PO4F 02829 and N N304172536) and the project Research Potential in Conservation and Sustainable Management of BiodiversityBIOCONSUS in the 7 th Framework Programme (contract no. 761245737). We are deeply indebted to R. Kozak for his help during fieldwork. We are grateful to all students, who participated in radio-tracking, and to M. Górny for his GIS support. Special thanks go to M. Glad.

Open Access This article is distributed under the terms of the Creative Commons Attribution 4.0 International License (http:// creativecommons.org/licenses/by/4.0/), which permits unrestricted use, distribution, and reproduction in any medium, provided you give appropriate credit to the original author(s) and the source, provide a link to the Creative Commons license, and indicate if changes were made.

\section{References}

Aanes R, Andersen R (1996) The effects of sex, time of birth, and habitat on the vulnerability of roe deer fawns to red fox predation. Can J Zool 74:1857-1865

Aguirre AA, Brojer C, Morner T (1999) Descriptive epidemiology of roe deer mortality in Sweden. J Wildl Dis 35:753-762

Apollonio M, Andersen R, Putman R (2010) European ungulates and their management in the 21 st century. Cambridge Univ Press, Cambridge

Bragina EV, Ives AR, Pidgeon AM, Kuemmerle T, Baskin LM, Gubar YP, Piquer-Rodrigues M, Keuler NS, Petrosyan VG, Radeloff VC (2015) Rapid declines of large mammal populations after the collapse of the Soviet Union. Conserv Biol 29:844-853

Cederlund G, Bergqvist J, Kjellander P, Gill R, Gaillard JM, Duncan P, Ballon P, Boisaubert B (1998) Managing roe deer and their impact on the environment: maximising benefits and minimising costs. In: Andersen R, Duncan R, Linnell JDC (eds) The European roe deer: the biology of success. Scandinavian Univ Press, Oslo, pp 337-372

Central Statistical Office (2011) Demographic yearbook of Poland. Central Statistical Office, Warsaw

Gaillard JM, Delorme D, Boutin J-M, Van Laere G, Boisaubert B, Pradel R (1993) Roe deer survival patterns: a comparative analysis of contrasting populations. J Anim Ecol 62:778-791

Gaillard JM, Andersen R, Delorme D, Linnell JDC (1998) Family effects on growth and survival of juvenile roe deer. Ecology 79:2878-2889

Heisey DM, Fuller TK (1985) Evaluation of survival and cause-specific mortality rates using telemetry data. J Wildl Manag 49:668-674

Jędrzejewska B, Jędrzejewski W, Bunevich AN, Miłkowski L, Krasiński ZA (1997) Factors shaping population densities and increase rates of ungulates in Białowieża Primeval Forest (Poland and Belarus) in the 19th and 20th centuries. ActaTheriol 42:399-451

Jędrzejewski W, Schmidt K, Theuerkauf J, Jędrzejewska B, Selva N, Zub K, Szymua L (2002) Kill rates and predation by wolves on ungulate populations in Białowieża Primeval Forest (Poland). Ecology 83: 1341-1356

Jędrzejewski W, Jędrzejewska B, Zawadzka B, Borowik T, Nowak S, Mysłajek RW (2008) Habitat suitability model for Polish wolves based on long-term national census. 11: 377-390

Kamler JF, Jędrzejewski W, Jędrzejewska B (2007) Survival and causespecific mortality of red deer Cervus elaphus in Białowieża National Park, Poland. Wildl Biol 13:48-52

Langvatn R, Loison A (1999) Consequences of harvesting on age structure, sex ratio and population dynamics of red deer Cervus elaphus in central Norway. Wildl Biol 5:213-223

Loison A, Festa-Bianchet M, Gaillard J-M, Jorgenson JT, Jullien J-M (1999) Age-specific survival in five populations of ungulates: evidence of senescence. Ecology 80:2539-2554

Melis C, Jędrzejewska B, Apollonio M, Bartoń K, Jędrzejewski W, Linnell JDC, Kojola I, Kusak J, Adamic M, Ciuti S, Delehan I, Dykyy I, Krapinec K, Mattioli L, Sagaydak A, Samchuk N, Schmidt K, Shkvyrya M, Sidorovich VE, Zawadzka B, Zhyla S (2009) Predation has a greater impact in less productive environments: variation in roe deer, Capreolus capreolus, population density across Europe. Glob Ecol Biogeogr 18:724-734

Muth M, Bowe JF (1998) Illegal harvest of renewable natural resources in North America: toward a typology of the motivations for poaching. Soc Nat Resour 11:9-24

Mysterud A, Tryjanowski P, Panek M (2006) Selectivity of harvesting differs between local and foreign roe deer hunters: trophy stalkers have the first shot at the right place. Biol Lett 2:632-635

Niedziałkowska M, Jędrzejewski W, Mysłajek RW, Nowak S, Jędrzejewska B, Schmidt K (2006) Environmental correlates of 
Eurasian lynx occurrence in Poland-large scale census and GIS mapping. Biol Conserv 133:63-69

Okarma H, Jędrzejewska B, Jędrzejewski W, Krasiński ZA, Miłkowski L (1995) The roles of predation, snow cover, acorn crop, and manrelated factors on ungulate mortality in Białowieża Primeval Forest, Poland. ActaTheriol 40:197-217

Okarma H, Jędrzejewski W, Schmidt K, Kowalczyk R, Jędrzejewska B (1997) Predation of Eurasian lynx on roe deer and red deer in Białowieża Primeval Forest, Poland. ActaTheriol 42:203-224

Pettorelli N, Gaillard J-M, Duncan P, Maillard D, Van Laere G, Delorme D (2003) Age and density modify the effects of habitat quality on survival and movements of roe deer. Ecology 84:3307-3316

Pollock KH, Winterstein SR, Bunck CM, Curtis PD (1989) Survival analysis in telemetry studies: the staggered entry design. J Wildl Manag 53:7-15

Ratcliffe PR, Mayle BA (1992) Roe deer biology and management. Forestry commission bulletin, vol 105. HMSO, London, pp 1-28
Reil D (2010) Estimating roe deer population size in the Białowieża Primeval Forest. Diploma thesis. Humboldt Universität zu Berlin, Germany

Sidorovich VE, Tikhomirova LL, Jędrzejewska B (2003) Wolf Canis lupus numbers, diet and damage to livestock in relation to hunting and ungulate abundance in northeastern Belarus during 1990-2000. Wildl Biol 9:103-111

Stubbe C (1997) Rehwild: Biologie, Ökologie, Bewirtschaftung. Blackwell Wissenschafts-Verlag, Berlin

Van Moorter B, Gaillard J-M, McLoughlin PD, Delorme D, Klein F, Boyce MS (2009) Maternal and individual effects in selection of bed sites and their consequences for fawn survival at different spatial scales. Oecologia 159:669-678

Wawrzyniak P, Jędrzejewski W, Jędrzejewska B, Borowik T (2010) Ungulates and their management in Poland. In: Apollonio M, Andersen R, Putman R (eds) European ungulates and their management in the 21st century. Cambridge Univ Press, Cambridge, pp $232-242$ 